\title{
ATIVIDADE ANTIFÚNGICA DO EXTRATO ALCOÓLICO DE PRÓPOLIS, ÁLCOOL DE CEREAIS E DO ÓLEO ESSENCIAL DE MANJERICÃO SOBRE BOTRYTIS CINEREA
}

\author{
Camila Rosana Wuaden ${ }^{1}$, Iloir Gaio ${ }^{2}$, Tuane Sperhacke ${ }^{2}$, Jhonatan Paulo Barro ${ }^{3}$, Paola Mendes Milanesi ${ }^{2}$ \\ ${ }^{1}$ Universidade do Estado de Santa Catarina - UDESC, Programa de Pós-Graduação em Ciências Ambientais, Lages, SC.. \\ ${ }^{2}$ Universidade Federal da Fronteira Sul (UFFS), Curso de Agronomia, Erechim, RS. ${ }^{3}$ Universidade Federal de Viçosa - \\ UFV, Programa de Pós Graduação em Fitopatologia, Viçosa, MG. E-mail: camila wuaden@hotmail.com
}

\section{RESUMO}

A uva é uma fruta amplamente aceita pelos consumidores, além de ser produzida em larga escala no Brasil. Entretanto é uma cultura muito suscetível a perdas em pré-colheita ocasionadas por doenças e, entre elas, pode-se citar a podridão cinzenta do cacho, cujo agente causal é o fungo Botrytis cinerea. A busca por formas alternativas para o controle desse patógeno pode minimizar o uso de agrotóxicos, garantindo um alimento mais seguro. Objetivou-se avaliar o potencial antifúngico in vitro do extrato alcoólico de própolis, álcool de cereais e óleo essencial de manjericão (Ocimum basilicum), autoclavados ou não, sobre o crescimento micelial de Botrytis cinerea, ao longo do tempo de exposição. Os tratamentos avaliados foram: extrato alcoólico de própolis e álcool de cereais, ambos nas concentrações $0,2,5,6,25,12,5 \%$; e óleo essencial de manjericão, nas concentrações $0,0,25,0,50,1 \%$. Para a obtenção do crescimento micelial foram realizadas medidas em sentidos diametralmente opostos, com um paquímetro digital, durante 0,24 , $48,72,96,120$ e $144 \mathrm{~h}$ de exposição, para o cálculo da taxa de inibição do crescimento micelial (ICM, \%). 0 experimento foi realizado em duplicata, sendo os tratamentos dispostos em esquema fatorial $4 \times 7$ (concentrações $x$ tempos) e os dados foram analisados por comparação de médias (teste de Tukey, $p \leq$ $0,05)$, desdobrando a interação, quando significativa. Todos os tratamentos contendo óleo essencial de manjericão autoclavado e não autoclavado foram eficientes na inibição do crescimento micelial de $B$. cinerea. A autoclavagem do extrato alcoólico de própolis proporciona maior eficácia para o controle do patógeno do que a não autoclavagem. Para o álcool de cereais, a autoclavagem interfere na eficiência de controle de $B$. cinerea.
\end{abstract}

Palavras-chave: Ocimum basilicum L.; controle alternativo; Vitis sp.; crescimento micelial; podridão cinzenta.

\section{ANTIFUNGAL ACTIVITY OF PROPOLIS ALCOHOLIC EXTRACT, GRAIN ALCOHOL, AND BASIL ESSENTIAL OIL ON BOTRYTIS CINEREA}

\begin{abstract}
Grape is a fruit widely accepted by consumers, besides being produced in large scale in Brazil. However, it is a crop very susceptible to losses in pre-harvest and, among the main diseases responsible for these losses, we can mention the gray rot of the bunch, whose causal agent is the fungus Botrytis cinerea. The search for alternative ways to control this pathogen can minimize the use of agrochemicals, ensuring a safer food. The aim of this study was to evaluate the in vitro antifungal potential of propolis alcoholic extract, cereal alcohol and basil oil (Ocimum basilicum), autoclaved or not, on the mycelial growth of Botrytis cinerea, during the exposure time. The treatments evaluated were: alcoholic extract of propolis and cereal alcohol, both in concentrations $0.0,2.5,6.25,12.5 \%$; and basil oil, at concentrations $0.25,0.50,1.00 \%$. In order to obtain the mycelial growth, measurements were carried out in diametrically opposite directions, with a digital caliper, during $0,24,48,72,96,120$ and 144 hours of exposure, to calculate the rate of inhibition of mycelial growth (IMG, \%). The experiment was performed in duplicate, with the treatments arranged in a factorial scheme $4 \times 7$ (concentrations $x$ times) and the data were analyzed by means comparison (Tukey's test, $p \leq 0.05$ ), unfolding the interaction, when significant. All treatments containing autoclaved and nonautoclaved basil essential oil were efficient in inhibiting the mycelial growth of $B$. cinerea. The autoclaving of the propolis alcoholic extract provides greater efficacy for the control of the pathogen than nonautoclaving. For cereal alcohol, autoclaving interferes with the control efficiency of $B$. cinerea.
\end{abstract}

Keywords: Ocimum basilicum L.; alternative control; Vitis sp.; mycelial growth; gray rot. 


\section{INTRODUÇÃO}

A ocorrência de doenças de final de ciclo é um agravante para a produção de uvas, pois estas reduzem a qualidade final do produto. Em videira, as podridões de cachos, tais como a amarga (Greeneria uvicola), a da uva madura (Glomerella cingulata) e a podridão (ou mofo) cinzenta(o), causada pelo fungo Botrytis cinerea Pers. Ex Fr. (AMORIM et al., 2016), estão entre as principais doenças que podem acarretar perdas significativas em todas as variedades de uvas (americanas, viníferas ou híbridas), principalmente para cultivares de cachos compactos, causando danos a campo. Tais podridões ocorrem principalmente sob condições de alta umidade relativa e temperaturas entre 15 e $28^{\circ} \mathrm{C}$ (CAMILI, 2004; SÔNEGO et al., 2003).

O controle da podridão cinzenta ainda é feito basicamente com 0 uso de fungicidas químicos, porém, em virtude do aumento da resistência do patógenos a tais produtos e diante de uma maior consciência ambiental e exigências dos mercados consumidores por produtos vegetais produzidos de forma sustentável e livres de contaminantes, a busca por novas formas de controle vem ganhando espaço (HAMANN, 2011). Os sistemas orgânicos de produção agrícola não permitem o uso de substâncias sintéticas e nisso, produtos naturais que possuem propriedades antifúngicas, tais como extratos e óleos de plantas, podem ser uma alternativa aos fungicidas sintéticos (SILVA et al., 2013).

A própolis é uma resina que possui muitas propriedades, sendo uma delas a fungitoxidade. $O$ uso de extrato alcoólico de própolis no controle de diversos fitopatógenos apresentou bons resultados para várias espécies de plantas cultivadas (MARINI, 2012; MONTIPÓ, 2010; PEREIRA et al., 2014). Já o óleo essencial de manjericão pode ter potencial de indução de resistência em algumas plantas contra fitopatógenos (SCHWAN-ESTRADA et al., 2012).

Dessa forma, o objetivo deste trabalho foi avaliar o potencial antifúngico in vitro de diferentes concentrações de extrato alcoólico de própolis e óleo essencial de manjericão (Ocimum basilicum L.) sobre o crescimento micelial de Botrytis cinerea, proveniente de videira (Vitis sp.), ao longo do tempo de exposição.

\section{MATERIAL E MÉTODOS}

Os ensaios foram realizados no Laboratório de Fitopatologia da Universidade Federal da Fronteira Sul - Campus Erechim (RS).
O micro-organismo Botrytis cinerea foi isolado de cachos de uva infectados pelo patógeno e cedido pelo Instituto Federal do Rio Grande do Sul Campus Bento Gonçalves. O patógeno foi cultivado em placas de Petri com meio de cultura batata-dextrose-ágar (BDA, Himedia ${ }^{\mathrm{TM}}$ ) e incubado em BOD a $25 \pm 2{ }^{\circ} \mathrm{C}$ e fotoperíodo de $12 \mathrm{~h}$, até o momento da montagem dos testes.

As folhas de manjericão (Ocimum basilicum L.) foram obtidas de um cultivo orgânico localizado no município de Peritiba - SC. As folhas foram coletadas e levadas ao laboratório, lavadas em água corrente e colocadas em solução de hipoclorito a $1 \%$ por 20 min., para sanitização superficial. Em seguida, as folhas foram novamente lavadas com água destilada para retirar o excesso de hipoclorito e deixadas em repouso por $24 \mathrm{~h}$ sobre o papel absorvente. Após, o material foi acondicionado em sacos de papel e colocado em estufa, com circulação de ar, a $40{ }^{\circ} \mathrm{C}$, durante $96 \mathrm{~h}$. Para o preparo do extrato de manjericão, o material seco foi triturado (CELOTO et al., 2008). O óleo essencial de manjericão foi obtido por hidrodestilação em aparelho Clevenger conforme metodologia descrita por Saggiorato et al. (2012).

A própolis foi cedida por apicultores da região de Erechim. Para a confecção do extrato alcoólico, inicialmente foi feita a solução estoque que continha $15 \%$ de própolis para o restante de álcool de cereais $70 \%(\mathrm{v} / \mathrm{v})$. Para facilitar a extração antes do preparo, a própolis foi moída. A mistura foi agitada a cada três dias, por aproximadamente 45 dias, sendo mantida sob temperatura ambiente e protegida da luz. Após esse período a mistura foi filtrada em papel Whatman no 1 e armazenada em frasco de vidro (GARCIA et al., 2004). O álcool de cereais também foi avaliado como um tratamento em função de ser o veículo para a obtenção do extrato de própolis.

Para avaliar o efeito do óleo essencial de manjericão, nas concentrações $0 ; 0,25 ; 0,50$ e $1 \%$; do extrato alcoólico de própolis e do álcool de cereais, nas concentrações $0 ; 2,5 ; 6,25$ e 12,5\%, sobre o crescimento micelial de Botrytis cinerea, os tratamentos foram misturados ao meio de cultura BDA antes e após a autoclavagem.

Após a solidificação dos meios de cultura contendo os tratamentos, foi feita a inoculação do fungo. Para isso, discos de $5 \mathrm{~mm}$ contendo micélio e conídios de $B$. cinerea foram depositados no centro das placas. Estes foram incubados a $25^{\circ} \mathrm{C}$, com fotoperíodo de $12 \mathrm{~h}$, por 
7 dias para a realização das avaliações do crescimento micelial $(\mathrm{mm})$, por meio de medidas em sentidos diametralmente opostos, com auxílio de um paquímetro digital. As medições foram realizadas durante sete dias a partir da inoculação. Para encontrar a taxa de inibição do crescimento micelial (ICM, \%) foi utilizado a seguinte fórmula (HILLEN et al., 2012):

ICM (\%) $=$ [(crescimento na testemunha crescimento no tratamento $\mathrm{Y}) /$ crescimento na testemunha] .100

O experimento foi conduzido em delineamento inteiramente casualizado, em esquema fatorial $4 \times 7$ (doses $\times$ tempos), com quatro repetições por tratamento, sendo analisado individualmente cada tratamento (óleo essencial de manjericão, extrato de própolis e álcool de cereais) com e sem autoclavagem. 0 experimento foi realizado em duplicata e os dados obtidos foram submetidos à análise de variância e as médias comparadas pelo teste de Tukey $(p \leq 0,05)$ com 0 auxílio do software estatístico ASSISTAT 7.7 beta (SILVA; AZEVEDO, 2009).

\section{RESULTADOS E DISCUSSÃO}

Todas as concentrações contendo o óleo essencial de manjericão, autoclavado e não autoclavado apresentaram propriedades antifúngicas, interferindo no crescimento micelial de Botrytis cinerea (Tabela 1). Para o óleo essencial de manjericão não houve diferença entre a autoclavagem e não autoclavagem, o que poderia evidenciar que as substâncias com propriedades antifúngicas presentes no óleo não seriam termossensíveis. Da mesma forma, as propriedades do extrato de outra espécie de manjericão (Ocimum gratissimum), também apresentam essa característica (RODRIGUES et al., 2006).

Os óleos essenciais apresentam bons resultados no controle de algumas doenças, tais como os obtidos de alecrim, candeia e palmarosa, que inibiram o crescimento micelial de Alternaria carthami, Alternaria sp. e Rhizoctonia solani (HILLEN et al., 2012). Já os óleos essenciais de capim-limão, palmarosa, citronela, cravo, canela, menta, lavanda, tangerina, eucalipto, alecrim e laranja foram testados sobre $B$. cinerea isolado de morangueiro. Todos os tratamentos a base de óleos essenciais demonstraram efeito semelhante a um fungicida recomendado para a cultura. Os melhores resultados foram com capim limão, palmarosa, canela e menta, sendo o capim limão e a canela, efetivos no caso de isolados resistentes (LORENZETI, 2011).

Para diversas espécies de manjericão, entre elas Ocimum basilicum L., há relatos de efeitos antimicrobianos. Essa atividade seria devido à presença de compostos nos óleos essenciais dessa espécie, como o Eugenol e o Linalol, que juntos apresentam sinergismo (KOROCH et al., 2017).

No tratamento com extrato de própolis, autoclavado e não-autoclavado, todas as concentrações foram eficientes no controle de $B$. cinerea, se comparado com a testemunha, não diferindo estatisticamente entre as concentrações e tempo de exposição, embora tenha sido observado que na maior concentração testada do extrato de própolis autoclavado, $12,5 \%$, não houve crescimento do patógeno. Porém, nas concentrações $2,5 \%$ e $6,25 \%$, foi observado um discreto crescimento a partir de 72 $\mathrm{h}$ e $96 \mathrm{~h}$, respectivamente, embora esses valores não tenham diferido estatisticamente das demais concentrações testadas. Para o extrato de própolis não autoclavado, os melhores resultados foram para as concentrações $6,25 \%$ e $12,5 \%$. Já na concentração $2,5 \%$, a partir de $96 \mathrm{~h}$, pode-se observar crescimento do fungo, sendo esta a menos inibitória (Tabela 1).

Já no tratamento com álcool de cereais autoclavado, não ocorreu crescimento do patógeno nas concentrações $6,25 \%$ e $12,5 \%$. O crescimento ocorreu apenas na concentração 2,5\%, a partir de $120 \mathrm{~h}$ de exposição ao tratamento. No tratamento álcool de cereais não autoclavado não houve crescimento significativo em nenhuma concentração testada, apenas na testemunha (Tabela 1).

A própolis possui grande quantidade de componentes químicos, que podem variar conforme a fauna local, incluindo flavonóides, ácidos aromáticos, terpenóides, fenilpropanóides, ácidos graxos entre outros compostos (LUSTOSA et al., 2008). Entre os benefícios dessa resina, pode-se citar as propriedades: anti-inflamatória; antibacteriana; antifúngica; e antioxidante. A intensidade da atividade é determinada pelas características químicas da resina, o que varia conforme o local de extração da própolis, pois ela está intimamente ligada com as espécies de abelhas produtoras, biodiversidade local e características climáticas (ZABAIOU et al., 2017). 
Tabela 1. Crescimento micelial $(\mathrm{mm})$ de Botrytis cinerea exposto ao extrato de própolis, álcool de cereais e óleo essencial de manjericão, autoclavados e não autoclavados, em diferentes concentrações e tempos.

\begin{tabular}{|c|c|c|c|c|c|c|c|c|}
\hline \multirow{2}{*}{ Concentração (\%) } & \multicolumn{7}{|c|}{ Tempos de exposição (h) } & \multirow{2}{*}{ CV (\%) } \\
\hline & 0 & 24 & 48 & 72 & 96 & 120 & 144 & \\
\hline \multicolumn{9}{|c|}{ Extrato de própolis - Autoclavado } \\
\hline 0 & $5,0 \mathrm{aE}^{*}$ & $5,0 \mathrm{aE}$ & $6,4 \mathrm{aE}$ & $23,2 \mathrm{aD}$ & $35,3 \mathrm{aC}$ & $39,9 \mathrm{aB}$ & 48,4 aA & \multirow{4}{*}{12,8} \\
\hline 2,5 & $5,0 \mathrm{aA}$ & $5,0 \mathrm{aA}$ & $5,0 \mathrm{aA}$ & 5,3 bA & $5,2 \mathrm{bA}$ & $5,9 \mathrm{bA}$ & $6,2 \mathrm{bA}$ & \\
\hline 6,25 & $5,0 \mathrm{aA}$ & $5,0 \mathrm{aA}$ & $5,0 \mathrm{aA}$ & $5,0 \mathrm{bA}$ & $5,1 \mathrm{bA}$ & $5,4 \mathrm{bA}$ & 5,7 bA & \\
\hline 12,5 & $5,0 \mathrm{aA}$ & $5,0 \mathrm{aA}$ & $5,0 \mathrm{aA}$ & $5,0 \mathrm{bA}$ & $5,0 \mathrm{bA}$ & $5,0 \mathrm{bA}$ & $5,0 \mathrm{bA}$ & \\
\hline \multicolumn{9}{|c|}{ Extrato de própolis - Não autoclavado } \\
\hline 0 & $5,0 \mathrm{aD}$ & $5,5 \mathrm{aD}$ & $8,5 \mathrm{aD}$ & $23,1 \mathrm{aC}$ & $33,9 \mathrm{aB}$ & $37,0 \mathrm{aB}$ & 45,0 aA & \multirow{4}{*}{19,4} \\
\hline 2,5 & $5,0 \mathrm{aC}$ & $5,0 \mathrm{aC}$ & $5,0 \mathrm{bC}$ & $5,3 \mathrm{bC}$ & $7,7 \mathrm{bBC}$ & $10,1 \mathrm{bAB}$ & $11,8 \mathrm{bA}$ & \\
\hline 6,25 & $5,0 \mathrm{aA}$ & $5,0 \mathrm{aA}$ & $5,0 \mathrm{bA}$ & $5,0 \mathrm{bA}$ & $5,0 \mathrm{bA}$ & $5,0 \mathrm{bA}$ & $5,0 \mathrm{bA}$ & \\
\hline 12,5 & $5,0 \mathrm{aA}$ & $5,0 \mathrm{aA}$ & $5,0 \mathrm{bA}$ & $5,0 \mathrm{bA}$ & $5,0 \mathrm{bA}$ & $5,0 \mathrm{bA}$ & $5,0 \mathrm{bA}$ & \\
\hline \multicolumn{9}{|c|}{ Álcool de cereais - Autoclavado } \\
\hline 0 & $5,0 \mathrm{aE}$ & $5,0 \mathrm{aE}$ & $6,4 \mathrm{aE}$ & $23,2 \mathrm{aD}$ & $35,3 \mathrm{aD}$ & 39,9 aB & 48,4 aA & \multirow{4}{*}{12,9} \\
\hline 2,5 & $5,0 \mathrm{aB}$ & $5,0 \mathrm{aB}$ & $5,0 \mathrm{bB}$ & $5,0 \mathrm{bB}$ & $5,0 \mathrm{bB}$ & $6,8 \mathrm{bAB}$ & 7,8 bA & \\
\hline 6,25 & $5,0 \mathrm{aA}$ & $5,0 \mathrm{aA}$ & $5,0 \mathrm{bA}$ & $5,0 \mathrm{bA}$ & $5,0 \mathrm{bA}$ & $5,0 \mathrm{bA}$ & $5,0 \mathrm{cA}$ & \\
\hline 12,5 & $5,0 \mathrm{aA}$ & $5,0 \mathrm{aA}$ & $5,0 \mathrm{bA}$ & $5,0 \mathrm{bA}$ & $5,0 \mathrm{bA}$ & $5,0 \mathrm{bA}$ & $5,0 \mathrm{cA}$ & \\
\hline \multicolumn{9}{|c|}{ Álcool de cereais - Não autoclavado } \\
\hline 0 & $5,0 \mathrm{aF}$ & $5,0 \mathrm{aF}$ & $8,5 \mathrm{aE}$ & $23,1 \mathrm{aD}$ & $33,9 \mathrm{aC}$ & $37,0 \mathrm{aB}$ & 45,0 aA & \multirow{4}{*}{11,3} \\
\hline 2,5 & $5,0 \mathrm{aA}$ & 5,0 aA & $5,0 \mathrm{bA}$ & 5,4 bA & $5,5 \mathrm{bA}$ & $5,6 \mathrm{bA}$ & 5,7 bA & \\
\hline 6,25 & $5,0 \mathrm{aA}$ & $5,0 \mathrm{aA}$ & $5,0 \mathrm{bA}$ & $5,0 \mathrm{bA}$ & $5,0 \mathrm{bA}$ & $5,0 \mathrm{bA}$ & $5,0 \mathrm{bA}$ & \\
\hline 12,5 & $5,0 \mathrm{aA}$ & $5,0 \mathrm{aA}$ & $5,0 \mathrm{bA}$ & $5,0 \mathrm{bA}$ & $5,0 \mathrm{bA}$ & $5,0 \mathrm{bA}$ & $5,0 \mathrm{bA}$ & \\
\hline \multicolumn{9}{|c|}{ Óleo essencial de manjericão - Autoclavado } \\
\hline 0 & $5,0 \mathrm{aE}$ & $5,0 \mathrm{aE}$ & $6,4 \mathrm{aE}$ & $23,2 \mathrm{aD}$ & $35,3 \mathrm{aC}$ & 39,9 aB & 48,4 aA & \multirow{4}{*}{12,3} \\
\hline 0,25 & $5,0 \mathrm{aA}$ & $5,0 \mathrm{aA}$ & $5,0 \mathrm{aA}$ & $5,0 \mathrm{bA}$ & $5,0 \mathrm{bA}$ & $5,0 \mathrm{bA}$ & $5,0 \mathrm{bA}$ & \\
\hline 0,5 & $5,0 \mathrm{aA}$ & $5,0 \mathrm{aA}$ & $5,0 \mathrm{aA}$ & $5,0 \mathrm{bA}$ & $5,0 \mathrm{bA}$ & $5,0 \mathrm{bA}$ & $5,0 \mathrm{bA}$ & \\
\hline 1,0 & $5,0 \mathrm{aA}$ & $5,0 \mathrm{aA}$ & $5,0 \mathrm{aA}$ & $5,0 \mathrm{bA}$ & $5,0 \mathrm{bA}$ & $5,0 \mathrm{bA}$ & $5,0 \mathrm{bA}$ & \\
\hline \multicolumn{9}{|c|}{ Óleo essencial de manjericão - Não autoclavado } \\
\hline 0 & $5,0 \mathrm{aF}$ & $5,5 \mathrm{aF}$ & $8,5 \mathrm{aE}$ & $23,1 \mathrm{aD}$ & $33,9 \mathrm{aC}$ & $37,0 \mathrm{aB}$ & 45,0 aA & \multirow{4}{*}{10,2} \\
\hline 0,25 & $5,0 \mathrm{aA}$ & $5,0 \mathrm{aA}$ & $5,0 \mathrm{bA}$ & $5,0 \mathrm{bA}$ & $5,0 \mathrm{bA}$ & $5,0 \mathrm{bA}$ & $5,0 \mathrm{bA}$ & \\
\hline 0,5 & $5,0 \mathrm{aA}$ & $5,0 \mathrm{aA}$ & $5,0 \mathrm{bA}$ & $5,0 \mathrm{bA}$ & $5,0 \mathrm{bA}$ & $5,0 \mathrm{bA}$ & $5,0 \mathrm{bA}$ & \\
\hline 1,0 & $5,0 \mathrm{aA}$ & $5,0 \mathrm{aA}$ & $5,0 \mathrm{bA}$ & $5,0 \mathrm{bA}$ & $5,0 \mathrm{bA}$ & $5,0 \mathrm{bA}$ & $5,0 \mathrm{bA}$ & \\
\hline
\end{tabular}

*Médias seguidas pela mesma letra minúscula na coluna e maiúscula na linha não diferem entre si pelo teste de Tukey $(p \leq 0,05)$. CV: Coeficiente de variação.

Marini (2012) testou a atividade antifúngica do extrato etanólico de própolis in vitro, contra Phakopsora euvitis Y. Ono, Pseudocercospora vitis (Lév.) Speg. e Elsinöe ampelina Shear, importantes patógenos da videira, e constatou que nas concentrações testadas, embora dose-dependente, houve efeito de fungitoxidade. Já, Celoto et al. (2008) testando vários extratos aquosos e hidroetanólicos encontraram resultados diferenciados, em que para alguns extratos a autoclavagem potencializou as propriedades antifúngicas e em outros teve efeito deletério. Ainda, em videira, extratos aquosos de plantas e extrato etanólico de própolis foram eficientes no controle de $B$. cinerea e Colletotrichum gloeosporioides (MONTIPÓ, 2010). 
Para as culturas anuais, o uso de extrato etanólico de própolis também apresentou bons resultados. Pereira et al. (2014) verificaram o efeito deste produto sobre a severidade da antracnose, o crescimento e a produtividade de feijão carioca, cv. 'IPR 139'. O uso do extrato, na concentração $4 \%$, reduziu a antracnose em até $63 \%$, o que refletiu no aumento da produtividade do feijoeiro. $O$ extrato aquoso de cravo-da-índia, a partir da concentração $5 \%$, promoveu a suspensão do crescimento de ambos os fungos in vitro. Já o extrato etanólico de própolis foi eficiente a partir da concentração $10 \%$. Nessa metodologia, os extratos foram adicionados ao meio após a autoclavagem.

O uso de extrato etanólico de própolis também apresentou efeito positivo na manutenção da qualidade em pós-colheita de fruta do dragão (Hylocereus polyrhizus (Weber) Britton \& Rose) durante o armazenamento. 0 tratamento mais promissor foi o extrato etanólico de própolis a $0,50 \%$, que tornou o amadurecimento lento e também aumentou a biossíntese de componentes nutricionais, como flavonóides e antioxidantes totais. Porém, as concentrações mais altas $(0,75 \%$ e $1,0 \%)$ apresentaram efeitos fitotóxicos na superfície da fruta, prejudicando a sua qualidade final (ZAHID et al., 2013).

Na tabela 2 é possível verificar que todos os tratamentos foram eficientes na inibição do crescimento micelial de Botrytis cinerea, com exceção da concentração $2,5 \%$ do extrato de própolis não autoclavado que, embora melhor que a testemunha, foi menos eficiente que os outros tratamentos. Não houve interação significativa entre as concentrações de cada tratamento e a autoclavagem (com ou sem).

Nas concentrações $6,5 \%$ e $12,5 \%$ não houve diferença entre extrato de própolis autoclavado e não autoclavado. Já na concentração 2,5\%, o extrato autoclavado apresentou inibição do crescimento micelial do patógeno de forma semelhante às outras concentrações, sugerindo que a autoclavagem poderia intensificar as propriedades antifúngicas do extrato testado.

Todos os tratamentos foram eficientes na inibição do crescimento micelial de Botrytis cinerea, com exceção da concentração $2,5 \%$ do extrato de própolis não autoclavado que, embora melhor que a testemunha, foi menos eficiente que os outros tratamentos (Tabela 2). Nas concentrações 6,5 e 12,5\% não houve diferença entre extrato de própolis autoclavado e não autoclavado. Já na concentração $2,5 \%$ o extrato autoclavado apresentou inibição do crescimento micelial do patógeno de forma semelhante às outras concentrações, sugerindo que a autoclavagem poderia intensificar as propriedades antifúngicas do extrato testado. 
Tabela 2. Inibição do crescimento micelial (ICM, \%) de Botrytis cinerea após a exposição a diferentes concentrações do extrato alcoólico de própolis, álcool de cereais e óleo essencial de manjericão, autoclavados e não autoclavados.

\begin{tabular}{|c|c|c|}
\hline \multirow{2}{*}{ Concentração (\%) } & \multicolumn{2}{|c|}{ Extrato alcoólico de própolis } \\
\hline & Autoclavado & Não autoclavado \\
\hline 0,0 & $0,0 \mathrm{bB}^{*}$ & $0,0 \mathrm{cB}$ \\
\hline 2,5 & 50,9 aA & $49,9 \mathrm{bA}$ \\
\hline 6,5 & $51,3 \mathrm{aA}$ & $55,7 \mathrm{aA}$ \\
\hline 12,5 & 51,7 aA & $55,7 \mathrm{aA}$ \\
\hline Média & 38,5 & 40,3 \\
\hline CV(\%) & 7,94 & 12,75 \\
\hline \multirow{2}{*}{ Concentração (\%) } & \multicolumn{2}{|c|}{ Álcool de cereais } \\
\hline & Autoclavado & Não autoclavado \\
\hline 0,0 & $0,0 \mathrm{bB}$ & $0,0 \mathrm{bB}$ \\
\hline 2,5 & $49,9 \mathrm{aA}$ & 54,6 aA \\
\hline 6,5 & 51,7 aA & 55,7 aA \\
\hline 12,5 & $51,7 \mathrm{aA}$ & $55,7 \mathrm{aA}$ \\
\hline Média & 38,3 & 41,5 \\
\hline $\mathrm{CV}(\%)$ & 7,9 & 6,46 \\
\hline \multirow{2}{*}{ Concentração (\%) } & \multicolumn{2}{|c|}{ Óleo essencial de manjericão } \\
\hline & Autoclavado & Não autoclavado \\
\hline 0,0 & $0,0 \mathrm{bB}$ & $0,0 \mathrm{bB}$ \\
\hline 0,25 & $51,7 \mathrm{aA}$ & 55,7 aA \\
\hline 0,50 & $51,7 \mathrm{aA}$ & $55,7 \mathrm{aA}$ \\
\hline 1,00 & $51,7 \mathrm{aA}$ & 55,7 aA \\
\hline Média & 38,8 & 41,8 \\
\hline $\mathrm{CV}(\%)$ & 7,48 & 5,12 \\
\hline
\end{tabular}

*Médias seguidas pela mesma letra minúscula na coluna e maiúscula na linha não diferem entre si pelo teste de Tukey $(p \leq 0,05)$. CV (\%): Coeficiente de variação.

Quanto à inibição do crescimento micelial de Botrytis cinerea pelo óleo de manjericão (Tabela 2), pode-se verificar que todas as doses avaliadas foram eficientes, diferindo da Testemunha. O fator autoclavagem para o óleo e suas respectivas concentrações, nas condições em que esse experimento foi conduzido, não apresentou interação significativa.

O óleo essencial de manjericão, além de ter seu uso já estabelecido na culinária, como condimento, também vem apresentando bons resultados no controle de fitopatógenos. Possui uma gama de componentes químicos que podem variar em função dos fatores ambientais e climáticos, sendo os principais o linalol, o $\alpha$ transbergamoteno, o germacreno $D$, o cubenol e o $y$-cadineno (FERNANDES et al., 2004). 0 efeito antimicrobiano do óleo de manjericão é atribuído principalmente à presença do linalol (MARTINS et al., 2010). Além disso, o potencial antifúngico do óleo essencial de manjericão também foi relatado na cultura do algodoeiro para o controle de Colletotrichum gossypii var. cephalosporioides (SANTOS et al., 2011). A utilização do óleo de manjericão também apresentou bons resultados no controle de Penicillium nalgiovense em salame italiano (SAGGIORATO et al., 2012), apontando a versatilidade de seu uso inclusive na tecnologia de alimentos.

Outros estudos usando óleo essencial de manjericão, na concentração $1 \mathrm{~mL} \mathrm{~L}{ }^{-1}$, para o tratamento de sementes de feijão-fava, observaram redução no percentual de incidência do Aspergillus spp., não diferindo estatisticamente do tratamento com fungicida. Já na concentração $1,07 \mathrm{~mL} \mathrm{~L}^{-1}$ do mesmo óleo, foi observado inibição máxima do Penicillium spp., superando o tratamento com fungicida. Para o controle de Rhizopus spp., o óleo mostrou-se eficiente a partir da concentração de $1,16 \mathrm{~mL} \mathrm{~L}^{-1} \mathrm{e}$ essas concentrações não interferiram na qualidade fisiológica da semente. Porém, concentrações acima de $1,5 \mathrm{~mL} \mathrm{~L}^{-1}$ podem ter efeito tóxico para a semente (GOMES et al., 2016).

No presente estudo obtiveram-se resultados que apontam para a eficiência do uso de controle alternativo para Botrytis cinerea, 
porém são necessários mais estudos para validar as melhores concentrações do extrato alcoólico de própolis e do óleo essencial de manjericão, bem como a condução de experimentos a campo que avaliem o comportamento desses tratamentos in vivo.

\section{CONCLUSÃO}

O extrato alcoólico de própolis e o óleo essencial de manjericão, em todas as concentrações testadas, controlam Botrytis cinerea.

A autoclavagem ou não, para o óleo essencial de manjericão, não interfere em sua eficácia para o controle de $B$. cinerea.

A autoclavagem do extrato alcoólico de própolis potencializa a sua eficácia no controle do patógeno, embora a não autoclavagem interfira apenas sobre o efeito da concentração $2,5 \%$.

Quando aplicada sobre o álcool de cereais, na concentração $2,5 \%$, a autoclavagem interfere sobre seu efeito para controle do patógeno, enquanto a não autoclavagem desse tratamento proporciona maior eficácia para o controle de $B$. cinerea em todas as concentrações testadas.

\section{REFERÊNCIAS}

AMORIM, L.; SPÓSITO, M.B.; KUNIYUKI, H. Doenças da videira. In: AMORIM, L.; REZENDE, J.A.M.; BERGAMIN FILHO, A.; CAMARGO, L.E.A. (Eds.). Manual de fitopatologia: doenças das plantas cultivadas. 5. ed. Ouro Fino: Agronômica Ceres, 2016. v.2, p. 745-758.

CAMILI, E.C. Avaliação de agentes bióticos e abióticos aplicados em pós-colheita na proteção de uva 'itália' contra Botrytis cinerea. 2004. 156f. Dissertação (Mestrado em Agronomia) Faculdade de Ciências Agronômicas da UNESP, Botucatu, 2004.

CELOTO, M.I.B.; PAPA, M.F.S.; SACRAMENTO, L.V.S.; CELOTO, F.J. Atividade antifúngica de extratos de plantas a Colletotrichum gloeosporioides. Acta Scientiarum Agronomy, Maringá, v. 30, n. 1, p. 1-5, 2008.

FERNANDES, P.C.; FACANALI, R.; TEIXEIRA, J.P.F.; FURLANI, P.R.; MARQUES, M.O.M. Cultivo de manjericão em hidroponia e em diferentes substratos sob ambiente protegido. Horticultura Brasileira, Brasília, v. 22, n. 2, p. 260-264, 2004.
GARCIA, R.C.; SÁ, M.E.P.; LANGONI, H.; FUNARI, S.R.C. Efeito do Extrato Alcoólico de Própolis sobre a Pasteurella multocida "in vitro" e em Coelhos. Acta Scientiarum Animal Sciences, Maringá, v. 26, n. 1, p. 69-77, 2004.

GOMES, R.S.S.; NUNES, M.C.; NASCIMENTO, L.C.; SOUZA, J.O; PORCINO, M.M. Eficiência de óleos essenciais na qualidade sanitária e fisiológica em sementes de feijão-fava (Phaseolus lunatus L.). Revista Brasileira de Plantas Medicinais, Campinas, v. 18, n.1, p. 279-287, 2016. http://dx.doi.org/10.1590/1983-084X/15 117.

HAMANN, F.A. Aspectos do controle biológico de Botrytis cinerea Pers. Ex. Fr. em videira. 2011. 81f. Dissertação (Mestrado em Agronomia) Programa de Pós-Graduação em Agronomia, Universidade Federal de Santa Maria, Santa Maria, 2011.

HILLEN, T.; SCHWAN-ESTRADA, K.R.F.; MESQUINI, R.M.; CRUZ, M.E.S.; STANGARLIN, J.R.; NOZAKI, $M$. Atividade antimicrobiana de óleos essenciais no controle de alguns fitopatógenos fúngicos in vitro e no tratamento de sementes. Revista Brasileira de Plantas Medicinais, Botucatu, v. 14, n. 3, p. 439-445, 2012.

http://dx.doi.org/10.1590/S1516$\underline{05722012000300003 .}$.

KOROCH, A.R.; SIMON, J. E.; JULIANI, H.R. Essential oil composition of purple basils, their reverted green varieties (Ocimum basilicum) and their associated biological activity. Industrial Crops and Products, Netherlands, v. 107, p. 526530, 2017.

https://doi.org/10.1016/j.indcrop.2017.04.066

LORENZETTI, E.R.; MONTEIRO, F.P.; SOUZA, P.E.; SOUZA, R.J.; SCALICE, H.K.; DIOGO JR. R.; PIRES, M.S.O. Bioatividade de óleos essenciais no controle de Botrytis cinerea isolado de morangueiro. Revista Brasileira de Plantas Medicinais, Botucatu, v. 13, especial, p. 619 627, 2011. http://dx.doi.org/10.1590/S1516$\underline{05722011000500019}$.

LUSTOSA, S.R.; GALINDO, A.B.; NUNES, L.C.C.; RANDAU, K.P.; ROLIM NETO, P.J. Própolis: atualizações sobre a química e a farmacologia.

Revista Brasileira de Farmacognosia, João Pessoa, v. 18, n. 3, p. 447-454, 2008. http://dx.doi.org/10.1590/S0102$\underline{695 \times 2008000300020}$. 
MARINI, D.; MENSCH, R.; FREIBERGER, M.B.; DARTORA, J.; FRANZENER, G.; GARCIA, R.C.; STANGARLIN, J.R. Efeito antifúngico de extratos alcoólicos de própolis sobre patógenos da videira. Arquivos do Instituto Biológico, São Paulo, v. 79, n. 2, p. 305-308,

2012. http://dx.doi.org/10.1590/S180816572012000200023.

MARTINS, A.G.L.A.; NASCIMENTO, A.R.; MOUCHREK FILHO, J.E.; MENDES FILHO, N.E.; SOUZA, A.G.; ARAGÃO, N.E.; SILVA, D.S.V. Atividade antibacteriana do óleo essencial do manjericão frente a sorogrupos de Escherichia coli enteropatogênica isolados de alfaces. Ciência Rural, Santa Maria, v. 40, n. 8, p. 1791-1796, 2010. http://dx.doi.org/10.1590/S0103$\underline{84782010005000127 .}$.

MONTIPÓ, S. Potencial antifúngico de produtos naturais sobre patógenos de videira (Vitis spp.). 2010. 69f. Trabalho de conclusão de curso, Universidade Estadual do Rio Grande do Sul, Bento Gonçalves, 2010.

PEREIRA, C.S; MAIA, L.F.P.; PAULA, F.S. Aplicação de extrato etanólico de própolis no crescimento e produtividade do feijoeiro comum. Revista Ceres, Viçosa, v. 61, n. 1, p. 098-104, 2014.

http://dx.doi.org/10.1590/S0034737X2014000100013.

RODRIGUES, É.A.; SCHWAN-ESTRADA, K.R.F.; STANGARLIN, J.R.; SACAPIM, C.A.; FIORI-TUTIDA, A.C.G. Potencial da planta medicinal Ocimum gratissimum no controle de Bipolaris sorokiniana em sementes de trigo. Acta Scientiarum

Agronomy, Maringá, v. 28, n. 2, p. 213-220, 2006. http://dx.doi.org/10.4025/actasciagron.v28i2.107 1 .

SAGGIORATO, A.G.; GAIO, I.; TREICHEL, H.; OLIVEIRA, D.; CICHOSKI, A.J.; CANSIAN, R.L. Antifungal Activity of Basil Essential Oil (Ocimum basilicum L): Evaluation In Vitro and on na Italiantype Sausage Surface. Food and Bioprocess

Technolgy, [S.I.], n. 5, p. 378-384, 2012. http://dx.doi.org/10.1007/s11947-009-0310-z.

SANTOS, B.; BONALDO, S.M.; SCHWAN-ESTRADA, K.R.F. Óleos essenciais de espécies florestais e medicinais no controle de ramulose (Colletotrichum gossypii var. cephalosporioides) em algodão. In: CONGRESSO BRASILEIRO DE AGROECOLOGIA, 7., 2011, Fortaleza. Anais ...
Fortaleza: Cadernos de Agroecologia, 2011, v.6, n. 2.

SCHWAN-ESTRADA, K.R.F. et al. Uso de extratos vegetais e cogumelos na indução de resistência de plantas a patógenos. In: SCHWAN-ESTRADA, K.R.F.; RODRIGUES, F.A.; FORTUNATO, A.A.; RESENDE, R.S. (Eds.). Indução de resistência em plantas a patógenos. Viçosa, MG: Universidade Federal de Viçosa, 2012. p. 9-28.

SILVA, C.M.; BOTELHO, R.V.; FARIA, M.D.R.; MATEUS, M.A.F. Influência do método de extração do cinamomo para controle da antracnose da videira. Ciência e Técnica Vitivinícola, Dois Portos, v. 28, n 1, p.8, jun. 2013.

SILVA, F. A. S.; AZEVEDO, C. A. V. Versão do programa computacional Assistat para o sistema operacional Windows. Revista Brasileira de Produtos Agroindustriais, Campina Grande, v.4, n.1, p.71-78, 2002.

SÔNEGO, O.R.; GARRIDO, L.R.; GRIGOLETTI JÚNIOR, A. Doenças fúngicas. In: SÔNEGO, O.R.; GARRIDO, L.R.; GRIGOLETTI JÚNIOR, A.; FAJARDO, T.V.M. (Eds.). Uva para processamento:

Fitossanidade. Brasília: EMBRAPA, Informações Tecnológica, 2003. p.11- 44.

ZABAIOU, N.; FOUACHE, A.; TROUSSON, A.; BARON, S.; LOBACCARO, J.M.A.

Biological properties of propolis extracts: Something new from an ancient product. Chemistry and Physics of Lipids, Netherlands, v. 207, p. 214-222, 2017. https://doi.org/10.1016/i.chemphyslip.2017.04.0 $\underline{05}$

ZAHID, N.; ALI, A.; SIDDIQUI, Y.; MAQBOOL, M. Efficacy of ethanolic extract of propolis in maintaining postharvest quality of dragon fruit during storage. Postharvest Biology and Technology, Netherlands, v. 79, p. 69-72, 2013.https://doi.org/10.1016/j.postharvbio.2013. $\underline{01.003}$

Recebido para publicação em 25/09/2017

Revisado em 24/03/2018

Aceito em 26/06/2018 